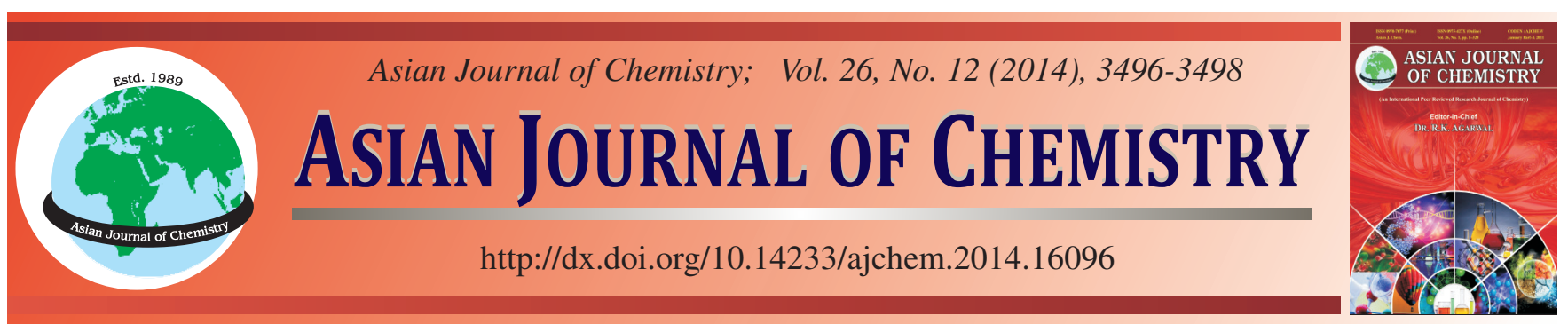

\title{
Synthesis and Evaluation of Novel Xanthone Derivatives as Potent AChE Inhibitors
}

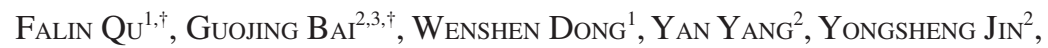 \\ QingGuo MenG ${ }^{3}$, QiUYe $\mathrm{Wu}^{2}$, Wei Guo ${ }^{1, *}$ and Shichong $\mathrm{Yu}^{2, *}$
}

\begin{abstract}
${ }^{1} 102$ Hospital of Chinese People's Liberation Army, 20 Heping North Road, Changzhou 213001, P.R. China
${ }^{2}$ Department of Organic Chemistry, School of Pharmacy, Second Military Medical University, 325 Guohe Road, Shanghai 200433, P.R. China ${ }^{3}$ College of Pharmacy, Yantai University, 30 Qingquan Road, Yantai 264005, P.R. China
\end{abstract}

*Corresponding authors: Fax: +86 21 81871225; Tel: +86 21 81871228-17; E-mail: yuscc@ @otmail.com; ysjin@ smmu.edu.cn Fax: +86 519 83064758; Tel: +86 519 83064501; E-mail: weiguo1022013@163.com

$\dagger$ These two authors contributed equally to this work.

A new series of xanthone derivatives have been designed, synthesized and evaluated as potent AChE inhibitors. Some of them showed more potent inhibitory activities to $\mathrm{AChE}$ than galanthamine. The most potent inhibitor xanthone derivative $2 \mathrm{a}$ inhibit $\mathrm{AChE}$ with a $\mathrm{IC}_{50}$ of $0.57 \mu \mathrm{M}$ and showed good $\mathrm{AChE} / \mathrm{BuChE}$ inhibition selectivity. Molecular docking studies were also performed to understand the detail information of interaction between $\mathrm{AChE}$ and inhibitor.

Keywords: Xanthone, Synthesis, AChE, Structure-activity relationship.

\section{INTRODUCTION}

Alzheimer's disease (AD) is a brain disease that causes problems with memory, thinking and behavior ${ }^{1}$. Acetylcholinesterase (AChE) inhibitors has been well known as the key drugs to control alzheimer's disease by improving the levels of acetylcholine (ACh) in brain ${ }^{2}$. AChE is an enzyme that degrades the neurotransmitter $\mathrm{ACh}$, producing choline and an acetate group ${ }^{3}$. It is mainly found at neuromuscular junctions and cholinergic synapses in the central nervous system, where its activity serves to terminate synaptic transmission.

Meanwhile, a variety of AChE inhibitors have been developed to treat alzheimer's disease (Fig. 1). For example, a series of N-methyl-N-(3-carbamoyloxyphenyl)methylamino xanthone derivatives (A) were designed by Rampa and co-workers ${ }^{4}$ with good selective inhibition for AChE over butyrylcholinesterase (BuChE). Tang and co-workers ${ }^{5}$ had developed some oxoisoaporphine and oxoaporphine derivatives as new dual inhibitors of AChE and BuChE. Furthermore, donepezil, an AChE inhibitor, was approved by the U.S. Food and Drug Administration in 1996 for the treatment of alzheimer's disease.

In recent years, we have focused on synthesizing and evaluating the biological activities of novel xanthone compounds $s^{6-8}$. Compound 1a, a small xanthone molecular, was identified to show good AChE inhibitory activity from high throughput screening (HTS) through varieties of xanthone derivatives. As shown in Fig. 1, the structure of $1 \mathbf{a}$ was simpler than the reported inhibitors and all its pharmacophores could be found in the reported ones. Moreover, it showed a $\mathrm{IC}_{50}$ of $0.66 \mu \mathrm{M}$ in the enzyme based assay, compared to $1.21 \mu \mathrm{M}$ for the positive control (Galantamine Hydrobromide, an AChE inhibitor). This finding encouraged us to undertake further investigation. Herein, we report our efforts to optimize the inhibitory effects of this compound by analyzing structureactivity relationships(SAR).
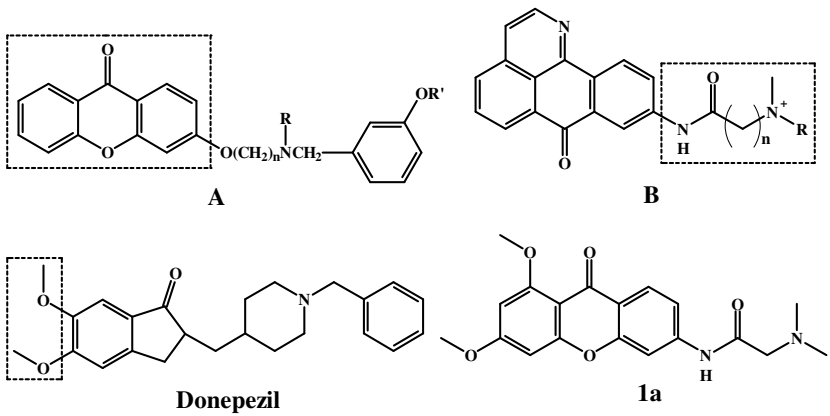

Fig. 1. Chemical structures of some inhibitors of AChE

\section{EXPERIMENTAL}

Melting points were determined with a Yamato MP-21 melting point apparatus and uncorrected. ${ }^{1} \mathrm{H}$ NMR and ${ }^{13} \mathrm{C}$ NMR spectra were recorded in $\mathrm{CDCl}_{3}$ or DMSO- $d_{6}$ unless otherwise indicated with a Bruker AC-300P spectrometer, using tetramethylsilane as an internal standard. ESI mass 
spectra were performed on an API-3000 LC-MS spectrometer. Elemental analysis was conducted with Carlo Erba1106 autoapparatus. Column chromatography was carried out on silica gel (200-300 mesh). The solvents and reagents were used as received or dried prior to use as needed. All reactions were monitored using thin-layer chromatography (TLC) on silica gel plates. Detection was effected by examination under UV light.

3-Dimethoxy-7-nitro-9H-xanthen-9-one (5): A solution of 5-nitro salicylic acid $(9.1 \mathrm{~g}, 0.05 \mathrm{~mol}), 1,3,5$-trimethoxybenzene $(8.5 \mathrm{~g}, 0.055 \mathrm{~mol})$ and Eaton's solution $100 \mathrm{~mL}$, was stirred at $110{ }^{\circ} \mathrm{C}$ for $4 \mathrm{~h}$, the reaction was complete, then cool down to room temperature, some ice water was added and stirred for another $2 \mathrm{~h}$ at rt, after filtration, the solid was washed with water, The residue was crystallized from $\mathrm{MeOH}$ to afford the compound 5 (12.0 g, $79 \%)$. ${ }^{1} \mathrm{H}$ NMR (300 MHz, DMSO$d_{6}$, TMS): $\delta 9.14$ (1 H, s, Ar), 8.47 (1 H, d, Ar), 7.50 (1 H, d, Ar), $6.55(1 \mathrm{H}, \mathrm{s}, \mathrm{Ar}), 6.42(1 \mathrm{H}, \mathrm{s}, \mathrm{Ar}), 4.01\left(3 \mathrm{H}, \mathrm{s}, \mathrm{OCH}_{3}\right), 3.95(3 \mathrm{H}$, s, $\left.\mathrm{OCH}_{3}\right)$. ESI-MS, $m / z$ : $[\mathrm{M}+\mathrm{H}]^{+}, 302.90$.

3-Dimethoxy-7-amino-9H-xanthen-9-one (6): A solution of 1,3-dimethoxy-7-nitro-9H-xanthen-9-one (3.01 g, $0.01 \mathrm{~mol}$ ), Raney-nickel $0.5 \mathrm{~g}$ and methanol $20 \mathrm{~mL}$ was stirred at room temperature, then hydrazine was added dropwised into the reaction slowly and stirred for another $4 \mathrm{~h}$ at rt. After filtration, the filtrate was evaporated under reduced pressure. The residue was crystallized from $\mathrm{MeOH}$ to afford the compound 6 (1.9 g, $69 \%)$. ${ }^{1} \mathrm{H}$ NMR $\left(300 \mathrm{MHz}, \mathrm{DMSO}-d_{6}, \mathrm{TMS}\right): \delta 7.52(1 \mathrm{H}, \mathrm{s}$, Ar), 7.22 (1 H, d, Ar), 7.00 (1 H, d, Ar), 6.47 (1 H, s, Ar), 6.32 $(1 \mathrm{H}, \mathrm{s}, \mathrm{Ar}), 3.98\left(3 \mathrm{H}, \mathrm{s}, \mathrm{OCH}_{3}\right), 3.91\left(3 \mathrm{H}, \mathrm{s}, \mathrm{OCH}_{3}\right), 3.77$ (2 H, br, NH). ESI-MS, $m / z:[2 \mathrm{M}+\mathrm{Na}]^{+}, 565.19$.

2-Chloro-N-(6,8-dimethoxy-9-oxo-9H-xanthen-2yl)acetamide (7): A solution of 7-amino-1,3-dimethoxy-9Hxanthen-9-one ( $2.71 \mathrm{~g}, 0.01 \mathrm{~mol})$, chloroacetyl chloride (1.68 g, $0.015 \mathrm{~mol}$ ) and toluene $50 \mathrm{~mL}$ was stirred reflux for about $2 \mathrm{~h}$. The reaction was complete, remove most of toluene under reduced pressure. Water was added to the residue, which was then extracted with ethyl acetate. The extract was washed with saturated $\mathrm{NaCl}$ solution, dried over anhydrous $\mathrm{Na}_{2} \mathrm{SO}_{4}$ and evaporated. Silica gel column chromatography of the residue afforded the compound 7 (3.1 g, $90 \%)$.

3-Chloro-N-(6,8-dimethoxy-9-0xo-9H-xanthen-2yl)propanamide (8): The reaction was run similarly to that used to synthesize the compound $\mathbf{8}$.

N-(6,8-dimethoxy-9-oxo-9H-xanthen-2-yl)-2-(dimethylamino)acetamide (1a): A solution of 2-chloro-N-(6,8-dimethoxy-9-oxo-9H-xanthen-2-yl)acetamide (694 mg, $2 \mathrm{mmol}$ ), $\mathrm{K}_{2} \mathrm{CO}_{3}(276 \mathrm{mg}, 2 \mathrm{mmol})$, dimethylamine (180 mL, $\left.4 \mathrm{mmol}\right)$ and DMF $10 \mathrm{~mL}$ was stirred at room temperature for about 10 h. After filtration, the filtrate was extracted with ethyl acetate, washed with water and saturated $\mathrm{NaCl}$ solution 3 times, dried over anhydrous $\mathrm{Na}_{2} \mathrm{SO}_{4}$ and evaporated. Silica gel column chromatography of the residue afforded the compound $1 \mathbf{a}$ (626 mg, $88 \%$ ).

The target compounds $\mathbf{1 b}-\mathbf{h}$ and $\mathbf{2 a - f}$ were synthesized by the same procedure as the compound $\mathbf{1 a}$.

\section{RESULTS AND DISCUSSION}

Compounds required for the establishment of structureactivity relationship were prepared as shown in Scheme-I starting from 2-hydroxy-4-nitrobenzoic acid (3). Reaction of 3 with 1,3,5-trimethoxybenzene (4) by using Eaton's reagent afforded xanthone $(\mathbf{5})^{9}$. Treat $\mathbf{5}$ with Raney nickel to reduce the nitro group gave 6 in high yield $(85 \%)^{10}$. Then, chloroacetyl chloride or 3-chloropropionyl chloride was added dropwisely into the flask containing $\mathbf{6}$ under reflux to give key intermediate $\mathbf{7}$ or $\mathbf{8}$. Reaction of $\mathbf{7}$ or $\mathbf{8}$ with different secondary amines formed the final xanthone sulfonamides $\mathbf{1 a - h}$ and $\mathbf{2 a - f}$ in high yield (Fig 2) ${ }^{11}$. The reactions were carried out in parallel. All new compounds were characterized by NMR and MS.

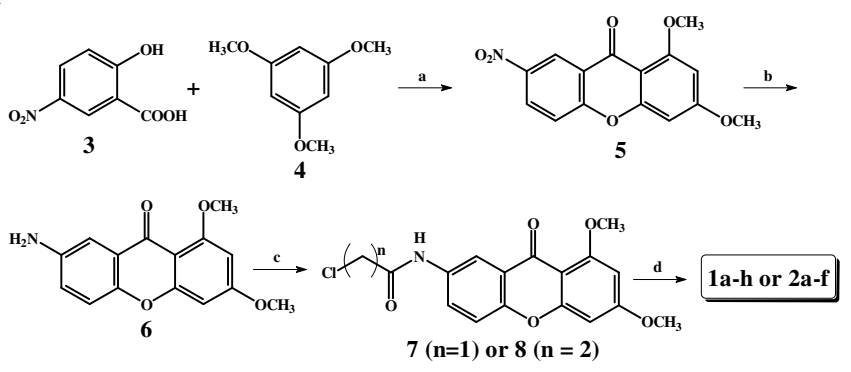

Reagents and conditions: (a) $\mathrm{P}_{2} \mathrm{O}_{5} / \mathrm{HSO}_{3} \mathrm{H}, 110{ }^{\circ} \mathrm{C}, 4 \mathrm{~h}, 75 \%$; (b) Raney nickel, hydrazine, $\mathrm{MeOH}$, room temperature, 2 h, $85 \%$; (c) Chloroacetyl chloride or 3-chloropropionyl chloride, toluene, reflux, 2 h, 90 \%; (d) Amine or azole, $\mathrm{K}_{2} \mathrm{CO}_{3}$, DMF, room temperature, $10 \mathrm{~h}, 72-88 \%$

Scheme-I: Synthesis of compounds $\mathbf{1 a - h}$ or $\mathbf{2 a - f}$

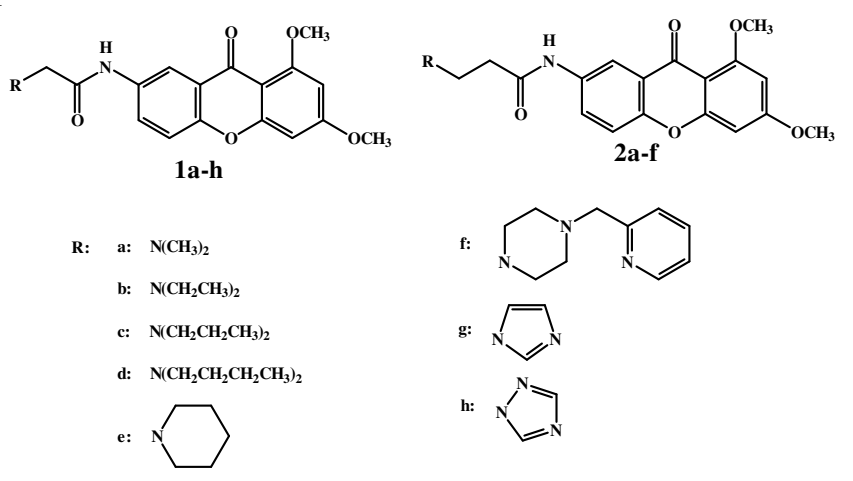

Fig. 2. Target xanthone derivatives

Evaluation of biological activities: To determine AChE and BChE inhibitory activities, all the compounds were measured in vitro according to the modified Ellman method with galanthamine as the positive control ${ }^{12}$. The selectivity of the compounds was also tested by determining their inhibitory activity against BuChE. The results were summarized in Table1. From the results, most of the tested compounds demonstrated good inhibitory activities against AChE. Compound 2a and 2e showed higher inhibitory activity than the positive control. Furhtermore, all the compounds showed weak activity against BuChE.

Structure-activity relationship (SAR): To explain the results, we proposed a likely binding mode for $1 \mathbf{e}$ to the active site of AChE based on computational docking results (Fig. $3)^{13}$. The designed compound could fit into the hydrophobic pocket formed by Tyr70, Asp72, Tyr121, Tyr334, Trp279. Moreover, the amide group could generate two hydrogen bond interaction with Asp72 and Tyr121. These results may provide some guidance for the development of novel AChE inhibitory lead structures. 


\begin{tabular}{ccc}
\hline \multicolumn{3}{c}{ TABLE-1 } \\
\multicolumn{3}{c}{$\begin{array}{c}\text { in vitro ChE (AChE AND BuChE) INHIBITION } \\
\text { ASSAY DATA FOR COMPOUNDS 1a-h and 2a-f }\end{array}$} \\
\hline \multirow{2}{*}{ Compound } & $\mathrm{AChE}$ & BuChE \\
& $\mathrm{IC}_{50}(\mu \mathrm{M})$ & Inhibitory ratio at $25 \mu \mathrm{M}$ \\
\hline $\mathbf{1 a}$ & $39.2^{\mathrm{a}}$ & 7.75 \\
$\mathbf{1 b}$ & 14.0 & 0.62 \\
$\mathbf{1 c}$ & $33.0^{\mathrm{a}}$ & - \\
$\mathbf{1 d}$ & $18.1^{\mathrm{a}}$ & - \\
$\mathbf{1 e}$ & 0.66 & 11.2 \\
$\mathbf{1 f}$ & 15.0 & - \\
$\mathbf{1 g}$ & $-\mathrm{b}$ & - \\
$\mathbf{1 h}$ & - & - \\
$\mathbf{2 a}$ & 0.57 & 26.0 \\
$\mathbf{2 b}$ & 2.93 & - \\
$\mathbf{2 c}$ & $50.6^{\mathrm{a}}$ & - \\
$\mathbf{2 d}$ & $52.6^{\mathrm{a}}$ & - \\
2e & 0.59 & - \\
$\mathbf{2 f}$ & $23.0^{\mathrm{a}}$ & 7.44 \\
Galanthamine & 1.21 & 58.2 \\
\hline
\end{tabular}

ainhibitory ratio at $12.5 \mu \mathrm{M},{ }^{b}$ no inibition observed, ${ }^{c}$ positive control

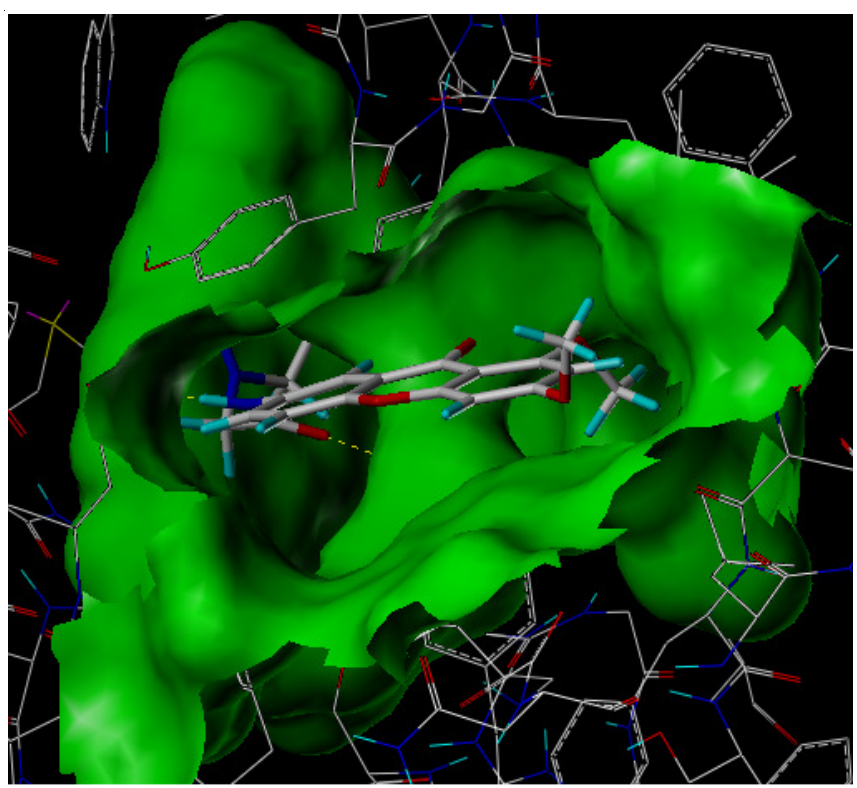

Fig. 3. Computed binding geometry of $\mathbf{1 e}$ in the active site of AChE

\section{Conclusion}

In summary, a series of new xanhtone derivatives $\mathbf{1 a - h}$, 2a-f as potential AChE inhibitors were synthesized in high yields. The biological screening of these compounds resulted in the identification of several potent $\mathrm{AChE}$ inhibitors with higher BChE/AChE selectivity, particularly compound 2n which is more potent than the established AChE inhibitor galanthamine. This observation was fitting to a molecular model resulting from the computational docking simulation, which showed that 1e could fit into the hydrophobic pocket of AChE. More effort was aimed at further SAR optimization and next round biological investigations, meanwhile our job identifying lead compounds in the half way will be well done soon and results will be reported in near future.

\section{ACKNOWLEDGEMENTS}

This work was supported by a grant from Science \& Technology Commission of Shanghai Municipality (No. 054319909 and 08JC1405500).

\section{REFERENCES}

1. V.N. Talesa, Mech. Ageing Dev., 122, 1961 (2001).

2. P. Camps, X. Formosa, C. Galdeano, T. Gómez, D. Muñoz-Torrero, M. Scarpellini, E. Viayna, A. Badia, M.V. Clos, A. Camins, M. Pallàs, M. Bartolini, F. Mancini, V. Andrisano, J. Estelrich, M. Lizondo, A. BidonChanal and F. Luque, J. Med. Chem., 51, 3588 (2008).

3. S. Darvesh, D.A. Hopkins and C. Geula, Nat. Rev. Neurosci., 4, 131 (2003).

4. A. Rampa, A. Bisi, P. Valenti, M. Recanatini, A. Cavalli, V. Andrisano, V. Cavrini, L. Fin, A. Buriani and P. Giusti, J. Med. Chem., 41, 3976 (1998).

5. H. Tang, Y.B. Wei, C. Zhang, F.X. Ning, W. Qiao, S.L. Huang, L. Ma, Z.S. Huang and L.Q. Gu, Eur. J. Med. Chem., 44, 2523 (2009).

6. H. Hu, H. Liao, J. Zhang, W. Wu, J. Yan, Y. Yan, Q. Zhao, Y. Zou, X. Chai, S. Yu and Q. Wu, Bioorg. Med. Chem. Lett., 20, 3094 (2010).

7. H.G. Hu, M.J. Wang, Q.J. Zhao, H.L. Liao, L.Z. Cai, Y. Song, J. Zhang, S.C. Yu, W.S. Chen, C.M. Liu and Q.Y. Wu, Chem. Nat. Compd., 43, 663 (2007).

8. H.G. Hu, M.J. Wang, Q.J. Zhao, S.C. Yu, C.M. Liu and Q.Y. Wu, Chin. Chem. Lett., 18, 1323 (2007).

9. P.E. Eaton, G.R. Carlson and J.T. Lee, J. Org. Chem., 38, 4071 (1973).

10. N.R. Ayyangar, K.C. Brahme, U.R. Kalkote and K.V. Srinivasan, Synthesis, 938 (1984).

11. Representative analytical data for compound 2a, yield $72 \%,{ }^{1} \mathrm{H}$ NMR (300 MHz, DMSO- $d_{6}$, TMS): $\delta 10.41(1 \mathrm{H}, \mathrm{br}, \mathrm{NH}), 8.25(1 \mathrm{H}, \mathrm{s}, \mathrm{Ar}), 7$, 96 (1H, br, Ar), 7.48 (1H, d, Ar), 6.66 (1H, s, Ar), 6.49 (1H, s, Ar), 3.88 $\left(3 \mathrm{H}, \mathrm{s}, \mathrm{OCH}_{3}\right), 3.83\left(3 \mathrm{H}, \mathrm{m}, \mathrm{OCH}_{3}\right), 3.83\left(2 \mathrm{H}, \mathrm{br}, \mathrm{CH}_{2}\right), 2.88-2.32$ $\left(6 \mathrm{H}, \mathrm{m}, \mathrm{CH}_{2}\right), 1.51-1.37\left(6 \mathrm{H}, \mathrm{m}, \mathrm{CH}_{2}\right)$. ESI-MS, $\mathrm{m} / \mathrm{z}$ : Calcd. 410.2, Found, 411.1 $[\mathrm{M}+\mathrm{H}]^{+}$.

12. G.L. Ellman, K.D. Courtney, V.J. Andres Jr. and R.M. Featherstone, Biochem. Pharmacol., 7, 88 (1961).

13. E.H. Rydberg, B. Brumshtein, H.M. Greenblatt, D.M. Wong, D. Shaya, L.D. Williams, P.R. Carlier, Y.P. Pang, I. Silman and J.L. Sussman, J. Med. Chem., 49, 5491 (2006). 